\title{
Drop Impact Analysis of Cushioning System with an Elastic Critical Component of Cantilever Beam Type
}

\author{
De Gao, ${ }^{1}$ Fu-de Lu, ${ }^{2}$ and Si-jia Chen ${ }^{1}$ \\ ${ }^{1}$ Ningbo Institute of Technology, Zhejiang University, Ningbo 315100, China \\ ${ }^{2}$ School of Aeronautics and Astronautics, Zhejiang University, Hangzhou 310027, China \\ Correspondence should be addressed to Fu-de Lu; lu673153@163.com
}

Received 25 March 2013; Revised 16 April 2013; Accepted 17 April 2013

Academic Editor: Jun Wang

Copyright (c) 2013 De Gao et al. This is an open access article distributed under the Creative Commons Attribution License, which permits unrestricted use, distribution, and reproduction in any medium, provided the original work is properly cited.

\begin{abstract}
In some electronic products and sculpture crafts, there are possibly vulnerable elements that can be idealized as cantilever beam type, failure of which will certainly lead the whole product to lose function. Based on the critical component of cantilever beam type, a nonlinear coupling dynamics model between the critical component and the item was established. The computing procedure of the model was designed using finite difference scheme. A numerical example shows that the acceleration changes notably with the length of the critical component, and the cantilevered end of the critical component is liable to be damaged, because the dynamic stress there is the largest. In this case, the maximum acceleration just cannot serve as the damaged criterion of the packaged goods, only with the maximum stress value. In order to avoid making a mistake, it is necessary to consider the critical component as an elastic element. The maximum stress of the cantilever beam surpasses the proportional limit of elastic components or is not an effective structural strength to determine whether the product loses its functions.
\end{abstract}

\section{Introduction}

The fragility of the products must be determined by a fragility assessment procedure before cushioning is provided. The maximum acceleration versus static stress is mostly used in cushion packaging, because the value of the acceleration is the criterion to assess whether the items are destroyed [1] or not. Newton first introduced fragility damage boundary curves by linking the input environment and the characteristics of critical component of packaged item [2], assuming the product as a spring-mass system. Newton's model is only suitable for brittle materials such as glass and hard plastics. Furthermore, inspection of many products after failure on the shock motion revealed plastic deformation $[3,4]$ like soft plastics, aluminum, and soft steels failed in a ductile mode. Burgess developed a rigid-plastic model to account for progressive failure and then obtained the elastic-plastic damage boundary theory. Many papers [5-11] developed damage boundary curves based on previous research results.

The studies cited above are all for mass-spring system; some researchers have studied the impact response of elastic vulnerable element of some products for which this simplified method is not suitable. Aiming at crafts, Xi and Peng [12] analyzed the response of the products with a vulnerable element that was idealized as a simple supported beam, and thought that the simple mass-spring system was not suited for evaluating the structural strength. The cantilever beam, simply supported beam, and bar element are also available in the microand portable electronic products [13-15]. Subir [16] certificated the criterion of the maximum stress that is responsible for structural strength, and the analytical modeling demonstrated the application of the measured acceleration as a criterion of the dynamic strength can be misleading if applied to elements of different dimensions, weight, and materials. Gao and Lu [17] studied the responses of the electronic products with bar type critical component, which is simplified as uniform and elastic parts. Abovementioned publications on crafts and portable electronic products have shown that it is the maximum stress, not the maximum acceleration, which is responsible for the dynamic strength of a structure.

This paper presents the dynamics model of expanded polyethylene foam cushioning system for products with 


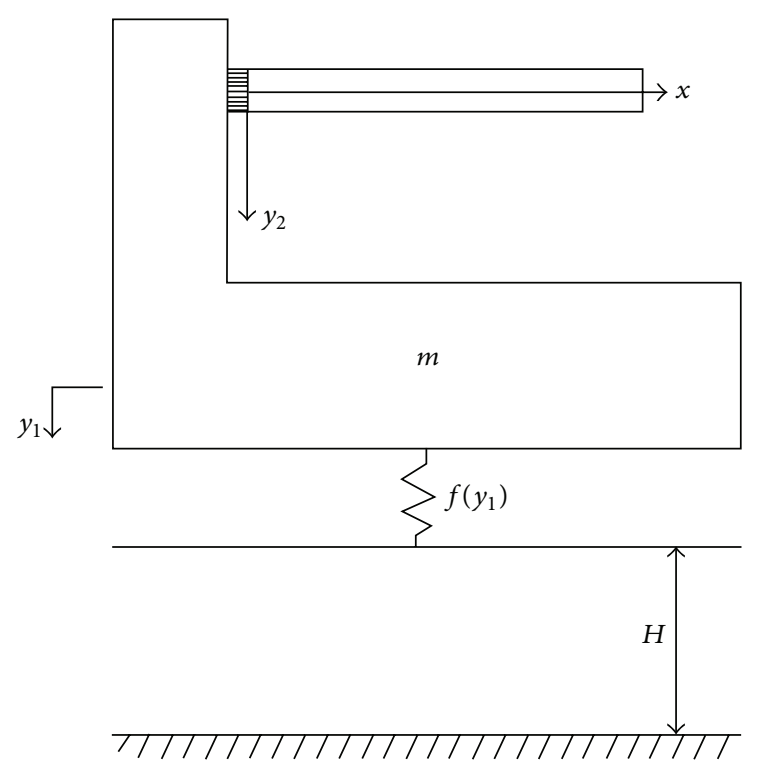

Figure 1: Packaging system with cantilever beam type critical component.

cantilever beam type vulnerable element, which is suitable for some portable electronic products or crafts with cantilever beam critical components, under drop impact loadings during transportation to introduce its application in cushioning packaging design.

\section{Coupling Packaging Dynamic Model}

The cantilever beam type structure mostly exists in electronic products, such as an electrical lead or intersect, and some crafts, such as the tail of sculpture animals, which is usually damaged functionally or physically due to the large-scale deformation of the critical component. Figure 1 shows a packaging system with the tangential type cushion pad, in which $m$ is the mass of the main part; $y_{1}$ is the displacement of the packaging item and $f\left(y_{1}\right)$ is the restoring force; $H$ is the dropping height of the packaging system.

A local coordinate system of the critical component was built, with origin $\mathrm{o}$ at the cantilever end, taking the axial direction of the beam as $x$ direction and the deflection as the $y_{2}$, as shown in Figure 2(a). Take the differential element $d x$ to analyze the movement of the critical component, as shown in Figure 2(b), where $E$ and $I$ are elastic modulus and section moments of inertia, respectively; $Q$ and $M$ are, respectively, shear force and bending moment of the section.

By Newton's second law, (1) is obtained based on Figure 2(b) as follows:

$$
\rho A_{0} d x \frac{\partial^{2} y_{2}}{\partial t^{2}}=-Q+\left(Q+\frac{\partial Q}{\partial x} d x\right) .
$$

Simplify the above as

$$
\rho A_{0} \frac{\partial^{2} y_{2}}{\partial t^{2}}=\frac{\partial Q}{\partial x}
$$

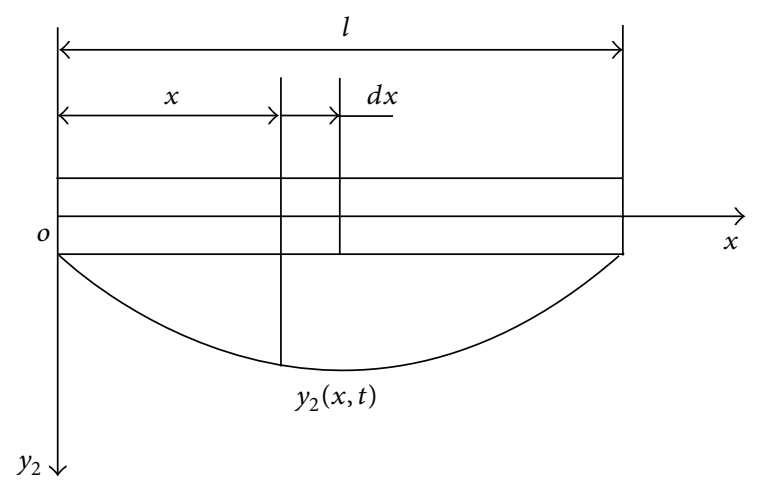

(a) Coordinate system of the critical component

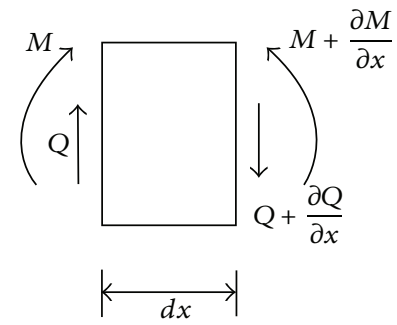

(b) Force diagram of infinitesimal section

FIgURE 2: Coordinate system of the critical component and force diagram of infinitesimal section.

where $\rho$ is the density of the beam and $A_{0}$ is the section area of the beam.

Based on the moment balance of the differential element, the following equation can be obtained:

$$
\left(M+\frac{\partial M}{\partial x} d x\right)-M-\left(Q+\frac{\partial Q}{\partial x} d x\right) d x=0
$$

Equation (3) can be further simplified as follows (4):

$$
Q=\frac{\partial M}{\partial x}
$$

Then insert (4) into (2) and get the following expression:

$$
\frac{\partial^{2} M}{\partial x^{2}}=\rho A_{0} \frac{\partial^{2} y_{2}}{\partial t^{2}}
$$

The relationship between the bending moment $M$ and the deflection $y_{2}$ is expressed as

$$
M=-E I \frac{\partial^{2} y_{2}}{\partial x^{2}}
$$

Combining (5) and (6), the movement equation of the critical component is given as

$$
E I \frac{\partial^{4} y_{2}}{\partial x^{4}}+\rho A_{0} \frac{\partial^{2} y_{2}}{\partial t^{2}}=0
$$


The vibration equation of the main part is given by

$$
m \ddot{y}_{1}+f\left(y_{1}, \dot{y}_{1}\right)+\left.E I \frac{\partial^{3} y_{2}}{\partial x^{3}}\right|_{x=0}=0
$$

where $f\left(y_{1}, \dot{y}_{1}\right)$ is the constitution relation of expanded polyethylene between the outer package and the product. Most of the cushioning materials for electronic products is EPE, and its relation [18] can be fitted by the tangential function:

$$
f(y)=A\left[a_{1} \frac{\dot{y}_{1}}{h}+a_{2} \tan \left(a_{3} \frac{y_{1}}{h}\right)\right],
$$

where $A$ and $h$ are, respectively, area and thickness of the cushion pad; $a_{1}, a_{2}$ and $a_{3}$ are the parameters determined by the experimental data.

With initial conditions and boundary conditions being considered, the coupling dynamic equation between the critical component and the main party is given as follows:

$$
\begin{gathered}
m \ddot{y}_{1}+A\left[a_{1} \frac{\dot{y}_{1}}{h}+a_{2} \tan \left(a_{3} \frac{y_{1}}{h}\right)\right]+\left.E I \frac{\partial^{3} y_{2}}{\partial x^{3}}\right|_{x=0}=0 \\
E I \frac{\partial^{4} y_{2}}{\partial x^{4}}+\rho A_{0} \frac{\partial^{2} y_{2}}{\partial t^{2}}=0 .
\end{gathered}
$$

The initial conditions and boundary conditions are

$$
\begin{gathered}
y_{1}(0)=y_{2}(x, 0)=0 ; \\
\dot{y}_{1}(0)=\left.\frac{\partial y_{2}(x, t)}{\partial t}\right|_{t=0}=\sqrt{2 g H} \\
y_{2}(0, t)=y_{1} ;\left.\quad \frac{\partial y_{2}(x, t)}{\partial x}\right|_{x=0}=0 ; \\
\frac{\partial^{2} y_{2}(x, t)}{\partial x^{2}}=\left.\frac{\partial^{3} y_{2}(x, t)}{\partial x^{3}}\right|_{x=l}=0 .
\end{gathered}
$$

The analytic solutions of (10) are not available due to the nonlinear behavior of cushion material used in this paper; therefore, only numerical solutions were obtained by different schemes.

It is assumed that the mass of the critical component is much smaller than the items in portable products, so the coupling between critical component and item can be neglected.

\section{Algorithm Design of the Model}

A different method was used to solve the coupling model shown in (10). The different schemes are introduced as follows:

$$
\begin{gathered}
\dot{y}_{1}(t)=\frac{y_{1}(t+\Delta t)-y_{1}(t-\Delta t)}{2 \Delta t} ; \\
\ddot{y}_{1}(t)=\frac{y_{1}(t+\Delta t)+y_{1}(t-\Delta t)-2 y_{1}(t)}{\Delta t^{2}} ; \\
\frac{\partial y_{2}(x, t)}{\partial t}=\frac{y_{2}(x, t+\Delta t)-y_{2}(x, t-\Delta t)}{2 \Delta t} ; \\
\frac{\partial^{2} y_{2}(x, t)}{\partial t^{2}}=\frac{y_{2}(x, t+\Delta t)+y_{2}(x, t-\Delta t)-2 y_{2}(x, t)}{\Delta t^{2}} ; \\
\frac{\partial^{2} y_{2}}{\partial x^{2}}=\frac{y_{2}(x+\Delta x, t)+y_{2}(x-\Delta x, t)-2 y_{2}(x, t)}{\Delta x^{2}} ; \\
\frac{\partial^{3} y_{2}}{\partial x^{3}}=\left(y_{2}(x+2 \Delta x, t)+2 y_{2}(x-\Delta x, t)\right. \\
\left.-2 y_{2}(x+\Delta x, t)-y_{2}(x-2 \Delta x, t)\right) / 2 \Delta x^{3} ; \\
\begin{array}{c}
\frac{\partial^{4} y_{2}}{\partial x^{4}}=\left(6 y_{2}(x, t)-4\left[y_{2}(x+\Delta x, t)+y_{2}(x-\Delta x, t)\right]\right. \\
\left.+\left[y_{2}(x+2 \Delta x, t)+y_{2}(x-2 \Delta x, t)\right]\right) / \Delta x^{4}
\end{array}
\end{gathered}
$$

So the movements $y_{1}$ and $y_{2}(x, t)$ can be obtained by combing (10) and (11), shown as

$$
z=y_{2}(x, t)-y_{1}(t)
$$

The maximum stress is determined as

$$
\sigma=\frac{M r}{I}
$$

where $r$ is the radius of the section of the critical component; $M$ is the bending moment and calculated by $M=$ $-E I\left(\partial^{2} y_{2} / \partial x^{2}\right)$.

3.1. Numerical Example. In the present study, an example was cited to illustrate the use of the dynamic model of the cushion packaging system with critical component of cantilever beam type. There is an electronic device with the mass $m=3 \mathrm{~kg}$, and the parameters of the critical component are as follows: density $\rho=0.5 \mathrm{~g} / \mathrm{cm}^{3}$, elastic modulus $E=100 \mathrm{MPa}$, proportional limit $\sigma_{p}=3.3 \mathrm{MPa}$, length $l=0.03 \mathrm{~m}$, and cross-sectional area $A_{0}=5 \mathrm{~mm}^{2}$. The parameters of the cushion material of expanded polyethylene between the outer packaging box and the product are $a_{1}=280 \mathrm{~Pa} \cdot \mathrm{s}, a_{2}=$ $0.0894 \mathrm{MPa}, a_{3}=1.91$, area $A=0.01 \mathrm{~m}^{2}$, and thickness $h=0.035 \mathrm{~m}$. The packaging system drops from the height $H=0.2 \mathrm{~m}$. It should be checked whether the cushion size satisfies the demand of engineering.

Substituting (12a), (12b), and (12c) into (10) and (11), the deformation, acceleration, and stress distribution are obtained, as shown in Figures 3-5. 


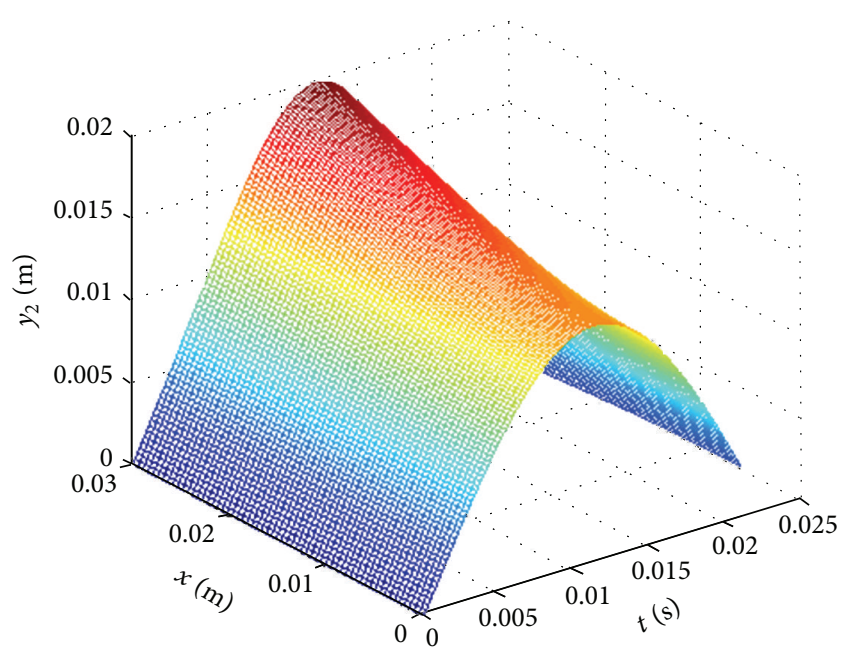

(a) The absolute displacement of the critical component

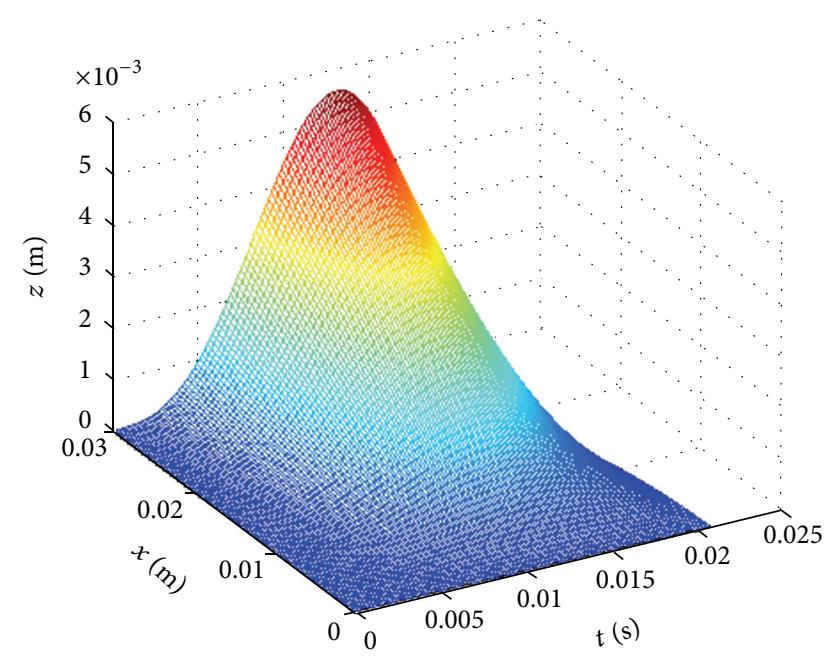

(b) The relative displacement of the critical component

FIgURE 3: Displacements of the critical component.

The absolute displacement $y_{2}$ and relative displacement $z$ are shown in Figures 3(a) and 3(b), respectively. It was shown that the absolute and relative displacements of the free end are maximum under the conditions that the other end of the cantilever beam is fixed on the product. Because elastic cantilever beam is vibrated under the impact loading condition, the displacement of cantilever beam relative to product item is obvious as shown in Figure 3(b).

The absolute acceleration and relative acceleration are shown in Figure 4. It can be seen that the absolute acceleration changed significantly with the length, and its maximum value is, respectively, $20.6 \mathrm{~g}$ and $63.5 \mathrm{~g}$ when the time $t=$ $0.0065, x=0$, and $t=0.0071, x=0.03 \mathrm{~m}$, as shown in Figure 4(a). To visualize the changes with the length of critical component, the relative acceleration of products and critical component is shown in Figure 4(b). It was demonstrated that the change law for acceleration response is similar to that of displacement response shown in Figure 3.

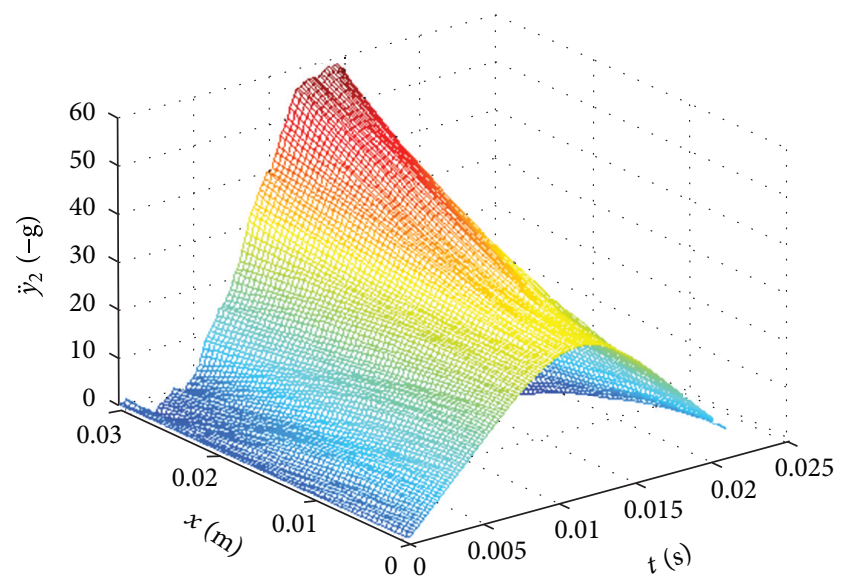

(a) The absolute acceleration of critical component

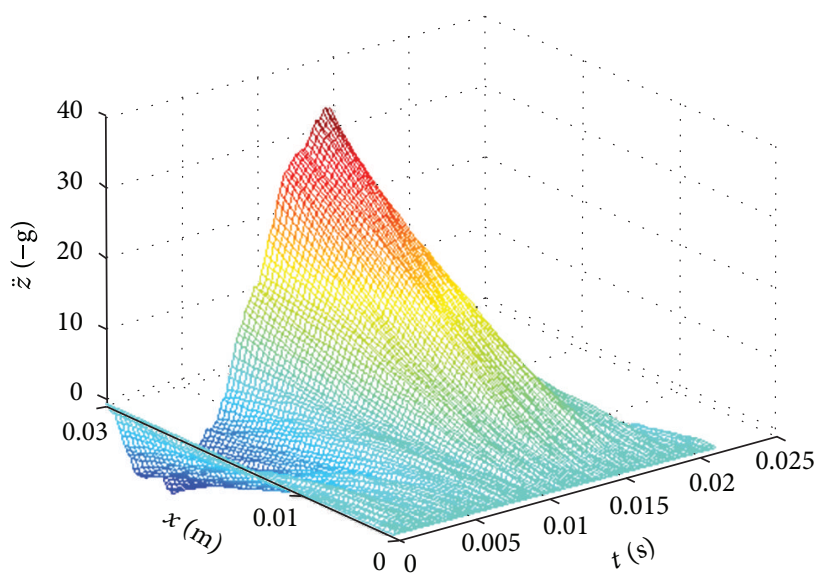

(b) The relative acceleration of critical component

FIGURE 4: The absolute acceleration and relative acceleration of critical component.

The changes of the stress of cantilever beam type with time and length are shown in Figure 5. The stress at the end of the cantilever beam $(2.71 \mathrm{MPa})$ is less than its proportional limit (3.3 MPa); thus, no plastic deformation occurred. Use of the maximum stress as a strength criterion for the improved dynamic strength of a vulnerable element can result in practical design decisions.

\section{Conclusions}

The packaging system with a critical component of cantilever beam type was studied by considering the nonlinear behavior of cushion material. Different schemes were used to obtain the numerical solution of the nonlinear packaging system with cantilever beam critical component.

As the critical component is of cantilever beam type, the displacement and acceleration of the free end are the largest; from the end to the free end of the cantilever, the relative displacement and acceleration changed gradually from zero to maximum. The beam stress reaches maximum at the end of the cantilever. It is concluded that the acceleration value is 


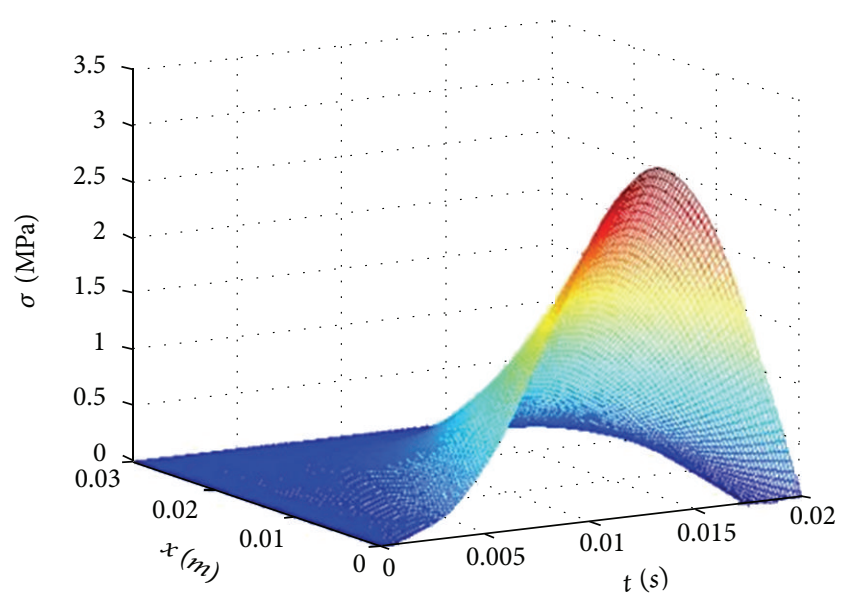

FIGURE 5: The relationships between the stress, time, and length.

not the criterion for judging whether the item is damaged or not and this only depends on whether the stress exceeds the proportional limit of the material.

\section{Acknowledgments}

This work was supported by the Twelfth National FiveYear Science and Technology Projects (nos. 2011BAD24B01, 2012BAD32B02).

\section{References}

[1] M. A. Sek, M. Minett, V. Rouillard, and B. Bruscella, "A new method for the determination of cushion curves," Packaging Technology and Science, vol. 13, no. 6, pp. 249-255, 2000.

[2] R. E. Newton, Fragility Assessment Theory and Practice, Monterey Research Laboratory, Monterey, Calif, USA, 1968.

[3] G. Burgess, "Product fragility and damage boundary theory," Packaging Technology and Science, vol. 1, no. 1, pp. 5-10, 1988.

[4] G. Burgess, "Effects of fatigue on fragility testing and the damage boundary curve," Journal of Testing and Evaluation, vol. 24, no. 6, pp. 419-426, 1996.

[5] Z. W. Wang, "Shock spectra and damage boundary curves for hyperbolic tangent cushioning systems and their important features," Packaging Technology and Science, vol. 14, no. 4, pp. 149-157, 2001.

[6] Z. W. Wang, "Dropping damage boundary curves for cubic and tangent package cushioning systems," Packaging Technology and Science, vol. 15, no. 5, pp. 263-266, 2002.

[7] Z. Wang, C. Wu, and D. Xi, "Damage boundary of a packaging system under rectangular pulse excitation," Packaging Technology and Science, vol. 11, no. 4, pp. 189-202, 1998.

[8] Z. W. Wang and J. H. Jiang, "Evaluation of product dropping damage based on key component," Packaging Technology and Science, vol. 23, no. 4, pp. 227-238, 2010.

[9] D. Gao and F. D. Lu, "Shock response of a nonlinear tangent packaging system with rotation," Journal of Vibration and Shock, vol. 29, no. 10, pp. 131.210-210.210, 2010.

[10] J. Wang, Z. W. Wang, L. X. Lu, Y. Zhu, and Y. G. Wang, "Three-dimensional shock spectrum of critical component for nonlinear packaging system," Shock and Vibration, vol. 18, no. 3, pp. 437-445, 2011.

[11] J. Wang, J. H. Jiang, L. X. Lu, and Z. W. Wang, "Dropping damage evaluation for a tangent nonlinear system with a critical component," Computers and Mathematics with Applications, vol. 61, no. 8, pp. 1979-1982, 2011.

[12] D. C. Xi and N. L. Peng, "Shockproof of the packaging for elastic parts with simple beam," Packaging Engineering, vol. 10, no. 1, pp. 42-48, 1989.

[13] S. H. Park and W. J. Kim, "Structural design of a Cathode-Ray Tube (CRT) to improve its mechanical shockproof character," Journal of Mechanical Science and Technology, vol. 20, no. 9, pp. 1361-1370, 2006.

[14] J. W. Yi and G. J. Park, "Development of a design system for EPS cushioning package of a monitor using axiomatic design," Advances in Engineering Software, vol. 36, no. 4, pp. 273-284, 2005.

[15] W. J. Kim, D. H. Kum, and S. H. Park, "Effective design of cushioning package to improve shockproof characteristics of large-sized home appliances," Mechanics Based Design of Structures and Machines, vol. 37, no. 1, pp. 1-14, 2009.

[16] E. Subir, "Is the maximum acceleration an adequate criterion of the dynamic strength of a structural element in an electronic product?" IEEE Transactions on Components Packaging and Manufacturing Technology A, vol. 20, no. 4, pp. 513-517, 1997.

[17] D. Gao and F. D. Lu, "Drop impact analysis of packaging system with bar type elastic critical components," Journal of Vibration and Shock, vol. 31, no. 15, pp. 47-49, 2012.

[18] D. Gao and F. D. Lu, "Optimization design of MDOF package cushioning system made of polyethylene," Journal of Vibration and Shock, vol. 31, no. 3, pp. 69-72, 2012. 


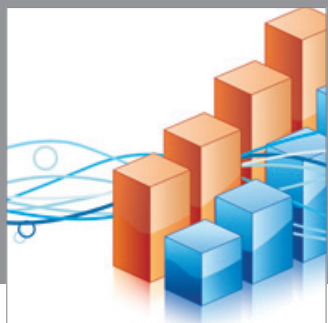

Advances in

Operations Research

mansans

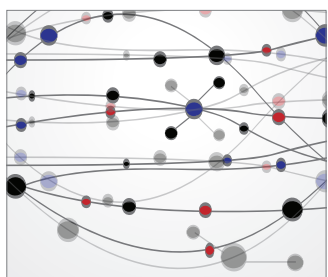

The Scientific World Journal
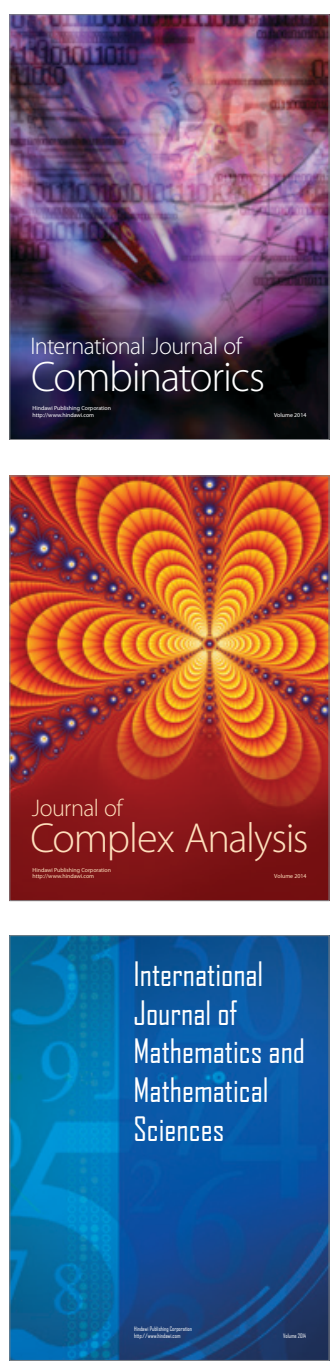
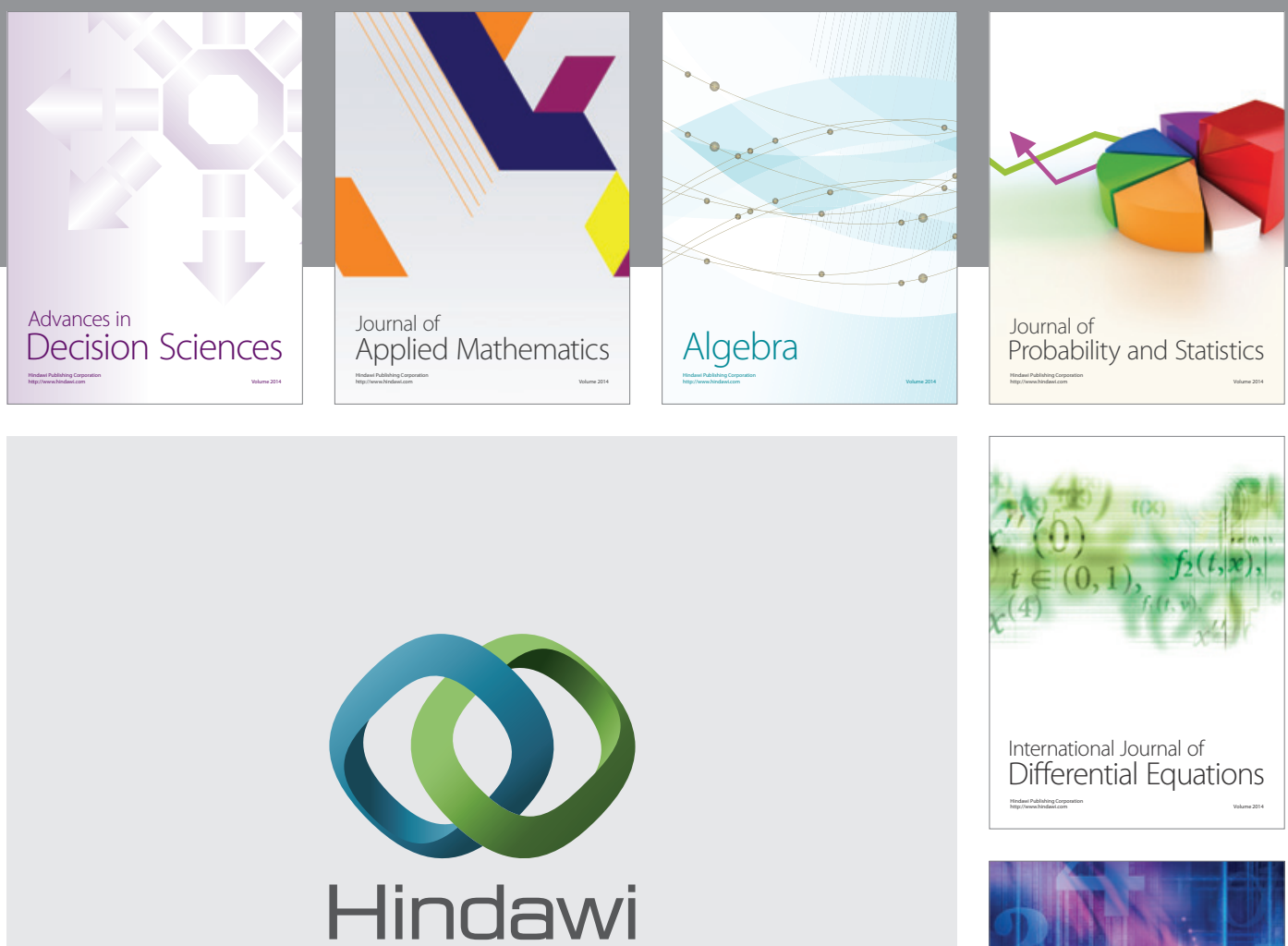

Submit your manuscripts at http://www.hindawi.com
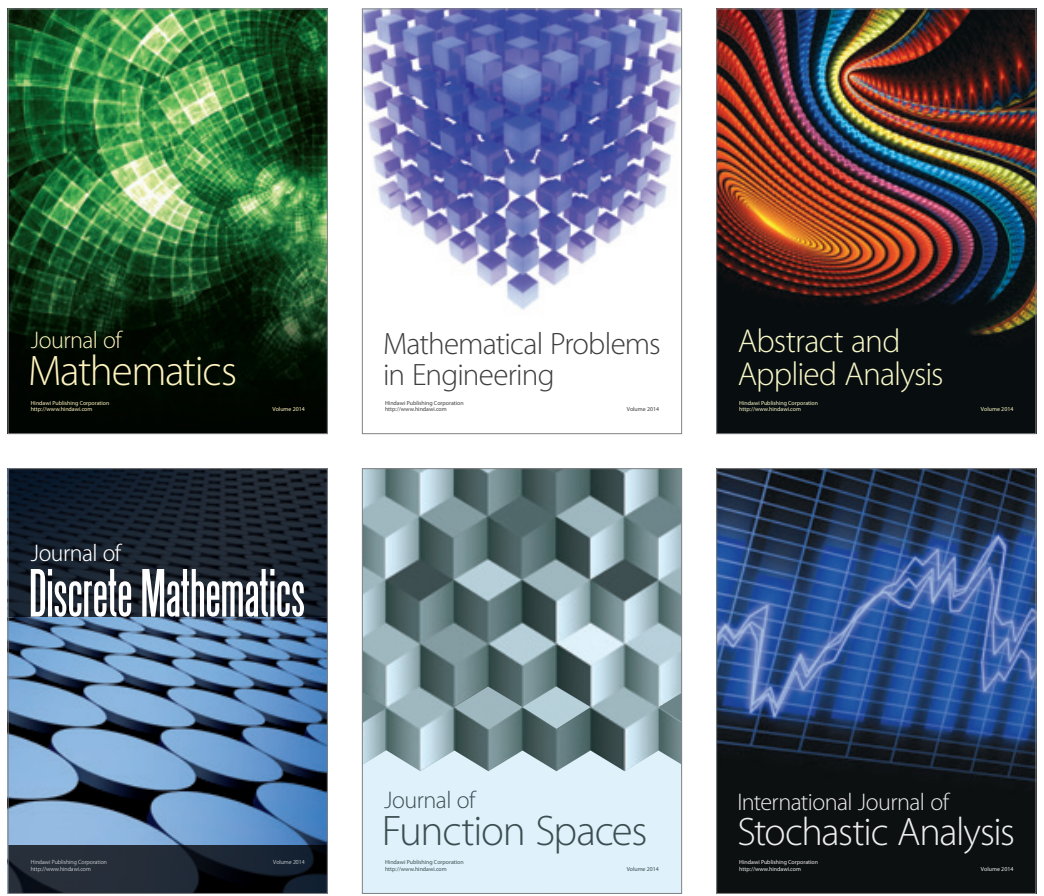

Journal of

Function Spaces

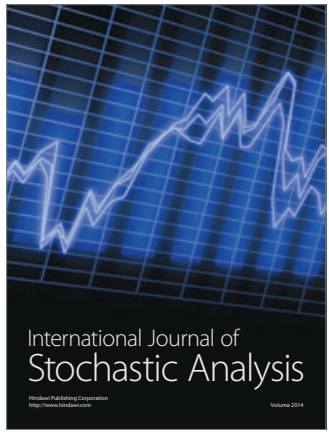

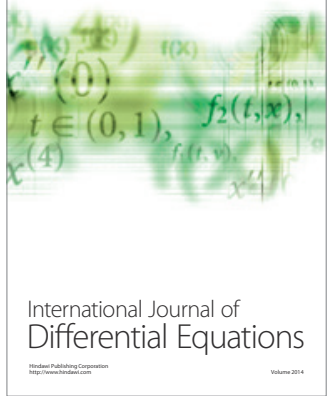
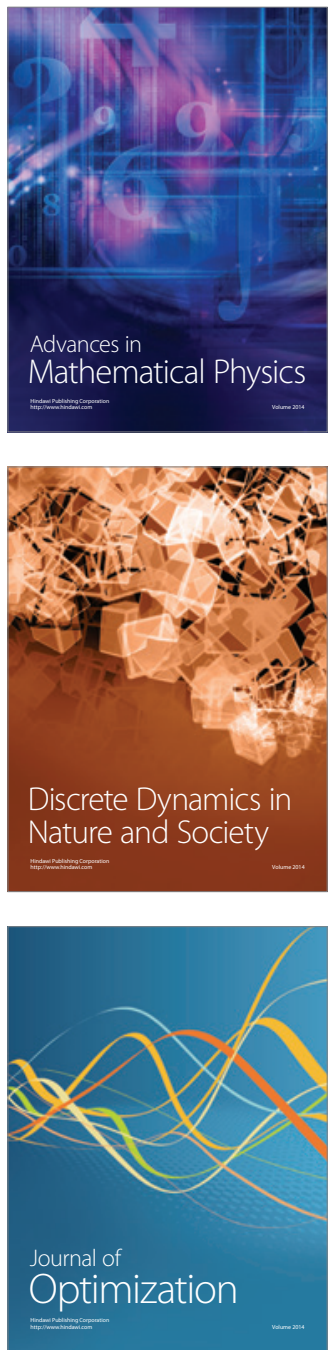